\title{
Gamma Irradiation Effect on the Thermal Stability, Optical and Electrical Properties of Acrylic Acid/ Methyl Methacrylate Copolymer Films
}

\author{
Yasser H. A. Fawzy ${ }^{1}$, Amr El-Hag Ali ${ }^{2}$, Ghada F. El-Maghraby ${ }^{1}$, Reda M. Radwan ${ }^{1,3}$ \\ ${ }^{1}$ Radiation Physics Department, National Center for Radiation Research and Technology (NCRRT), Atomic Energy Authority (AEA), \\ Nasr City, Cairo, Egypt; ${ }^{2}$ Polymer Chemistry Department, National Center for Radiation Research and Technology (NCRRT); \\ ${ }^{3}$ Community College, Jazan University, Kingdom of Saudi Arabia. \\ Email: redaradwan_2000@yahoo.com,redaradwan_2000@hotmail.com
}

Received January $5^{\text {th }}, 2011$; revised February $20^{\text {th }}, 2011$; accepted February $23^{\text {rd }}, 2011$.

\begin{abstract}
Copolymer films of Acrylic acid/Methyl methacrylate AAc/MMA with comonomer composition of 60/40 was prepared and then irradiated by gamma irradiation. The effect of irradiation on some of the physical properties of the copolymer films was investigated. The dose level ranged from 5 to $200 \mathrm{kGy}$. The thermo gravimetric analysis (TGA) showed that the thermal stability of the films increased with irradiation dose up to $100 \mathrm{kGy}$ then it started to decrease. The results of the UV-Visible spectroscopy of the films showed a decrease in the values of optical band gap and band tail width with doses starting from $100 \mathrm{kGy}$. The DC conductivity $\left(\sigma_{D C}\right)$ of the films was found to decrease to about three orders of magnitude from its original value with irradiation dose up to $100 \mathrm{kGy}$ then it started to increase with higher doses. Moreover, the dielectric constant and dielectric loss values were found to increase with dose up to $100 \mathrm{kGy}$ which may be attributed to the increase in the number of dipoles in the films due to the irradiation of the copolymer films in air. The results indicated that crosslinking dominated over chain scission in the copolymer films with irradiation dose up to $100 \mathrm{kGy}$ then at higher doses, chain scission dominated.
\end{abstract}

Keywords: Copolymers, Aac/MMA, Optical Properties, Dielectric Properties, Gamma Polymerization

\section{Introduction}

In recent years, radiation is used for polymer processing and modification. The irradiation of polymeric materials with ionizing radiation (e.g. gamma rays, X-rays, accelerated electrons and ion beams) leads to the formation of very reactive intermediates, free radicals, ions and excited states. These intermediates can follow several reaction paths that result in disproportion, hydrogen abstraction, arrangements and/or the formation of new bonds. The main interaction of ionizing radiation with polymers concerns its molecular weight is its ability to induce crosslinking or scission which may results in the formation of a wide range of materials without introducing any chemical initiators and without dissolving the sample. Generally, cross-linking and chain scission occur simultaneously but one of them may dominant over the other [Banford HM et al., 1998; Andrzej G. Chmielewski et al., 2005; Sangita
Rajvaidya et al.,2006]. Many industries are based on polymer radiation crosslinking technologies such as wire and cable insulation, applications in rubber tires and radiation vulcanization of rubber latex [Andrzej G. Chmielewski et al., 2005]. Vinyl polymers having hydrogen atom substituents $\left(-\mathrm{H}_{2} \mathrm{C}-\mathrm{CHR}-\right)_{\mathrm{n}}$, such as Poly acrylic acid $\left(-\mathrm{H}_{2} \mathrm{C}-\mathrm{CHCOOH}-\right)_{\mathrm{n}}$, undergo dominant hemolytic rupture of the $\mathrm{C}-\mathrm{H}$ bonds to form hydrogen-free radicals which crosslink with each other [R. Mishra et al., 2001]. Other kinds of polymers such as poly methyl methacrylate PMMA $\left(-\mathrm{H}_{2} \mathrm{C}-\mathrm{C}\left(\mathrm{CH}_{3}\right) \mathrm{COOCH} 3-\right)_{n}$ undergoes dominant main-chain scission and the liberation of $-\mathrm{COOCH}_{3}$ side groups occurs for every main-chain scission as a result of irradiation. [Hiroshi Yoshida et al., 1995].

Acrylic acid/ Methyl methacrylate (AAc/MMA) copolymers are used in wide range of bioapplications such 
as bioadhesives and drug delivery carriers [Tadaaki Inoue et al., 1998]. Also in technological applications such as light emitting diodes and organic based lasers [R. Sosa Fonseca et al., 2001]. Poly methyl-methacrylate (MMA) has attracted much attention for use as optical components and in opto-electronic devices due to its high transparency, low cost and volume productivity [F. Yakuphanoglu et al., 2007]

In this present study, A series of AAc/MMA copolymer films with comonomer composition of 60/40 respectively was prepared using $\gamma$ - irradiation induced polymerization. The prepared copolymer films were subsequently irradiated by gamma irradiation over irradiation doses up to $200 \mathrm{kGy}$. The optical properties and thermal stability of the copolymer were examined by UV-Visible spectroscopic analysis and thermo-gravimetric Analysis (TGA) respectively. Also their electrical properties were studied.

\section{Experimental}

\subsection{Materials}

Acrylic acid, (AAc) (Merk, Germany) of purity $99 \%$ was used as received, Methyl methacrylate, (MMA) (Merk, Germany) of purity $99 \%$ was used as received and Acetone (Aldich, Germany).

\subsection{Preparation of AAc/MMA Copolymer Films}

A constant amount of AAc and MMA were added to acetone and mixed well using vortex. Copolymerization of AAc with MMA was done by using ${ }^{60} \mathrm{Co} \gamma$-rays as initiator with dose of $40 \mathrm{kGy}$ at a dose rate of $4.62 \mathrm{kGy} / \mathrm{h}$ using a gamma cell available in NCRRT, AEA, Cairo, Egypt. Equal amounts of the produced copolymer solution were poured into a Petri dish (glass) and dried at room temperature for 72 hours.

\subsection{Irradiation Process}

The films were exposed to gamma radiation from the same ${ }^{60} \mathrm{Co}$ source used in the preparation step. The irradiation process was performed in air at room temperature. The irradiation doses was 5, 10, 25, 30, 50, 100, 150 and $200 \mathrm{kGy}$ with dose rate of $4.62 \mathrm{kGy} / \mathrm{h}$.

\subsection{Thermo-Gravimetric Analysis (TGA)}

The weight percentage studies versus temperature were performed by using Thermo-gravimetric Analysis (TGA) system of type Perkin Elmer Pyris 6 TGA, Germany. Ten $\mathrm{mg}$ of the dried samples were used for the analysis. Temperature was cycled from 30 to $600^{\circ} \mathrm{C}$ at a rate of $10^{\circ} \mathrm{C} / \mathrm{min}$ in a nitrogen atmosphere where the nitrogen flow was kept at constant rate of about $50 \mathrm{ml} / \mathrm{min}$ to prevent thermal oxidation processes of polymer samples.

\subsection{UV-Visible Spectroscopic Analysis}

Determination of the absorbance spectra of the copolymer films were carried out using JACSO V-560 UV-Vis spectrophotometer, Japan, in wavelength range from 200-900 nm.

\subsection{Electric Measurements}

The electrical measurements of all films were performed using a locally designed electrical circuit. An air drying type of silver paste was applied to the opposite surfaces of polymer samples in a sandwich configuration to ensure good electrical contacts. For the DC measurements, the samples were placed by a special designed cell in an oven. The temperature of the samples was monitored using a K-type thermocouple attached with digital thermometer type Tri-Sense, Cole - Parmer, USA, with temperature resolution of $0.1^{\circ} \mathrm{C}$. The sample temperature was varied within a range of $300-400{ }^{\circ} \mathrm{K}$. A Keithley digital electrometer of the type 6517 A, USA was used for the determination of the DC resistance of the films. The AC measurements were carried out using the Hioki LCR meter of the type $3531 \mathrm{Z} \mathrm{Hi-Tester,} \mathrm{Japan,} \mathrm{operat-}$ ing at a frequency range $(100 \mathrm{~Hz}-1 \mathrm{MHz})$, with impedance accuracy ranging from $0.15 \%$ up to $4 \%$. The dielectric measurements were performed at room temperature in a frequency range $(100 \mathrm{~Hz}-1 \mathrm{MHz})$. The LCR meter was connected to the computer through an Rs-232c interface.

\section{Results and Discussion}

\subsection{Thermo-Gravimetric Analysis (TGA)}

The thermal stability of the films was tested by TGA technique over a temperature range from room temperature up to $600^{\circ} \mathrm{C}$. Figure 1 shows the weight percentage versus temperature of the films.

In Figure $1 \mathrm{AAc}$ shows its four degradation steps at $100,250,400$, and $450^{\circ} \mathrm{C}$ which are due to the loss of associated water, anhydride formation, decarboxylation and backbone degradation respectively [A. El-Hag Ali et al, 2003] while MMA was characterized by weight losses at 203 and $380^{\circ} \mathrm{C}$ which can be attributed to desorption of water and complete decomposition [Erjun Tang et al, 2006; Maria Omastova et al, 1997]. Also it is clear that the thermal stability increases with the irradiation dose up to $100 \mathrm{kGy}$ then it decreases again for doses 150 and $200 \mathrm{kGy}$. This is maybe due to that irradiation with doses up to $100 \mathrm{kGy}$ increased the degree of crosslinking in the AAc/MMA copolymer films which hindered the flux of degradation. Then for higher doses (150 and $200 \mathrm{kGy}$ ) 


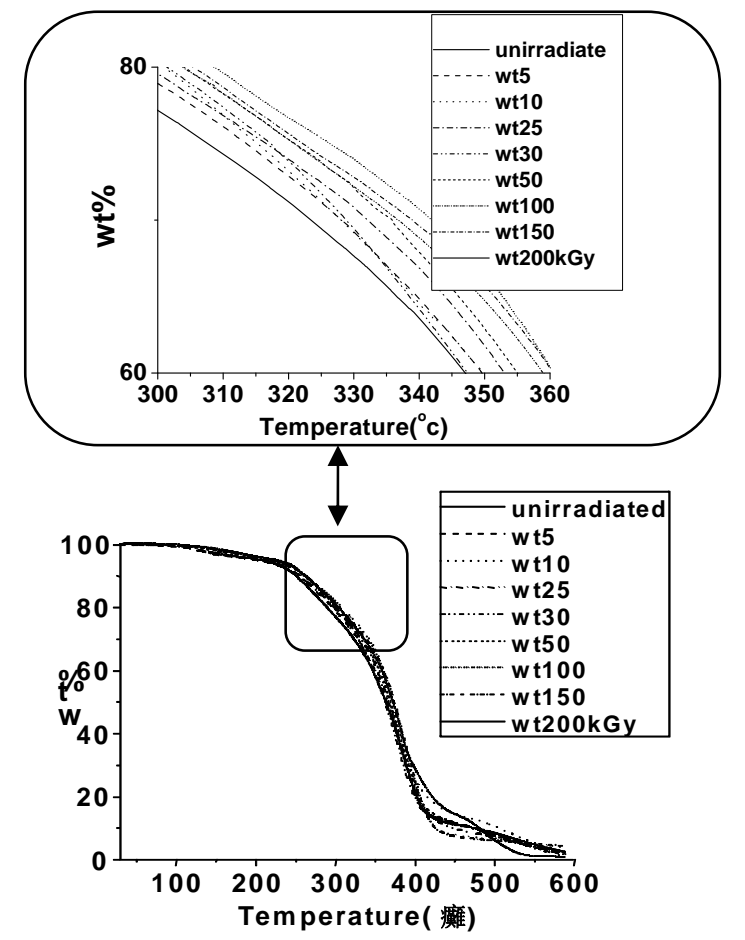

Figure 1. The weight percentage versus temperature of the AAc/MMA copolymer films.

chain scission started to dominate over crosslinking causing lower thermal stability. [L.C. Lopérgolo et al, 2000; Maria Omastova et al, 1997].

\subsection{UV-Visible Spectroscopic Analysis}

$\mathrm{UV}-\mathrm{V}$ is analysis was performed on the studied samples. The absorbance spectra are shown in Figure 2. It can be noted that the samples which was irradiated with higher doses (100, 150 and $200 \mathrm{kGy})$ have absorption edges that are shifted towards longer wavelengths.

According to the band theory of solids, the absorption coefficient $(\alpha)$ can be calculated from Urbach rule as:

$$
I(t)=I_{o} e^{-a t}
$$

where $I_{0}$ and $I(t)$ are the intensities of the incident and transmitted light, respectively and $t$ is the film thickness. As the absorption coefficient depends on the photon energy (hv), the relation between them can be expressed as:

$$
a h n=A\left(h n-E_{g}\right)^{s}
$$

where $\mathrm{A}$ is a constant and $\mathrm{E}_{\text {opt }}$ is the optical energy gap. Here $s$ represents an index that can take any of the values: $1 / 2,3 / 2,2$ or 3 depending on the type of transition responsible for the absorption.

The simplest way to deduce the type of transition is to examine the value of $r$, which fits hv to $\alpha$ hv with a

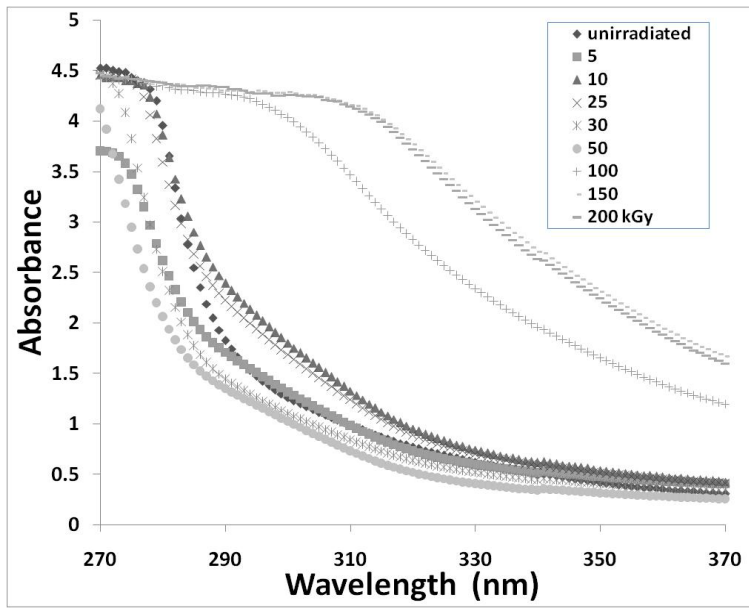

Figure 2. The absorbance spectra of the AAc/MMA copolymer films.

straight line relationship. In our case, $s=1 / 2$ which means an allowed direct transition. The estimated values of the optical band gap of the samples are listed in Table 1.

For more characterization of the optical behavior of AAc/MMA films, the band tail width values were determined using the Urbach rule as:

$$
\alpha=B \exp \left(h v / E_{a}\right)
$$

where $\mathrm{B}$ is a constant and $E_{a}$ is the band tail width. The estimated values of the band tail width of the films are listed in Table 1.

In Table 1 one can see that the irradiation process has no significant effect on both band gap and the band tail width values from the unirradiated sample to the irradiated up to $50 \mathrm{kGy}$; however at higher doses 100, 150 and $200 \mathrm{kGy}$ the band gap and band tail width values are decreased compared with those of the lower doses. Those results indicate that irradiation at higher doses 100, 150 and $200 \mathrm{kGy}$ affect the copolymer to crosslink. The crosslinking of the copolymer is caused by the formation of new covalent bonds and therefore new different chains were obtained which in turn hindered the motion of molecules and reduce their activity and, consequently decrease the optical band gap and the band tail width. [H. M. Abdel-Hamid et al, 2005; R. Mishra et al, 2000; F. Sharaf et al, 1995].

\subsection{Electric Measurements}

\subsubsection{Measurements}

$(I-V)$ characteristics were performed for all prepared films in the range $(0-200 \mathrm{~V})$. ( $I-V)$ characteristics indicated linear Ohmic behavior. An applied voltage value of $100 \mathrm{~V}$ was selected in measuring $\sigma_{D C}$ and the active- 
Table 1. The values of optical band gap of allowed direct transitions and band tail width and their correlation coefficients of the AAc/MMA copolymer films.

\begin{tabular}{cccc}
\hline $\begin{array}{c}\text { Dose } \\
(\mathbf{~ k G y})\end{array}$ & $\begin{array}{c}\text { Optical band gap } \\
E_{g}(\mathbf{e V})\end{array}$ & $\begin{array}{c}\text { Band tail width } \\
E_{a}(\mathbf{e V})\end{array}$ & $\mathbf{R}^{2} \mathbf{( \% )}$ \\
\hline unirradiated & 4.3 & 2.97 & 99.91 \\
$\mathbf{5}$ & 4.324 & 3.98 & 99.91 \\
$\mathbf{1 0}$ & 4.27 & 2.28 & 99.94 \\
$\mathbf{2 5}$ & 4.298 & 2.3 & 99.92 \\
$\mathbf{3 0}$ & 4.38 & 2.56 & 99.90 \\
$\mathbf{5 0}$ & 4.45 & 2.92 & 99.94 \\
$\mathbf{1 0 0}$ & 3.62 & 0.877 & 99.91 \\
$\mathbf{1 5 0}$ & 3.45 & 0.708 & 99.93 \\
$\mathbf{2 0 0}$ & 3.485 & 0.894 & 99.93 \\
\hline
\end{tabular}

tion energy of the samples. The values of electrical conductivity $\sigma_{D C}\left(\Omega^{-1} \mathrm{~m}^{-1}\right)$ of the samples versus the irradiation doses are shown in Figure $\mathbf{3}$ and listed in Table 2.

From the obtained results one can notice that the irradiation may induce crosslinking of the AAc/MMA filmswhich in turns reduces the DC conductivity of the samples. It was suggested that the decrease in $\sigma_{\mathrm{DC}}$ is due to the formation of some defects in the energy gap as a result of $\gamma$ - irradiation [R.M. Radwan et al., 2008]. These defects (sometimes called traps or clusters) create barriers against the mobility of charge carriers (electrons) already existing in non-irradiated polymeric materials.

The DC conductivity decreased from $1.61 \times 10^{-7}$ of the unirradiated sample to $2.05 \times 10^{-10}$ of that irradiated with $100 \mathrm{kGy}$ by approximately more than three orders of magnitude. At the $150 \mathrm{kGy}$ we can see that the irradiation started to break the branched chains and therefore increased the conductivity until the value $2.23 \times 10^{-8}$ of the $200 \mathrm{kGy}$ has been reached. This result is in agreement with the results obtained from the UV-Visible spectroscopy and TGA analysis.

The dependence of the DC conductivity $\left(\sigma_{D C}\right)$ on temperature $(\mathrm{T})$ for the produced copolymer films was investigated. Figure 4 shows the plot of $\ln \sigma_{D C}$ (T) vs. $1 / \mathrm{T}$ for the copolymer films over a temperature range $\left(300<\mathrm{T}<400{ }^{\circ} \mathrm{K}\right)$. For the proposed temperature range, the conductivity was found to increase with an increase of temperature for all films. For which, it is clear that the plots follow Arrehenius behavior throughout the four regions having four values of activation energy. The values of activation energy $\Delta E_{a}(\mathrm{eV})$ of the samples and their correlation coefficients are listed in Table 3.

The DC conductivity $\left(\sigma_{D C}(\mathrm{~T})\right)$ values of the films in all areas exhibit the validity of applying Arrhenius equation.

$$
\sigma_{D C}(T)=\sigma_{o} \exp \left(-\Delta E_{a} / K T\right)
$$

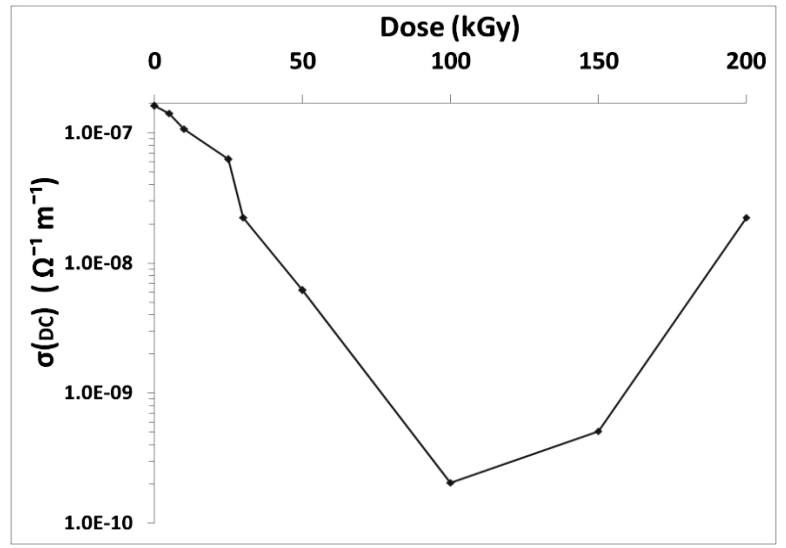

Figure 3. The DC conductivity $\left(\sigma_{\mathrm{DC}}\right)$ versus irradiation dose for AAc/MMA copolymer films.

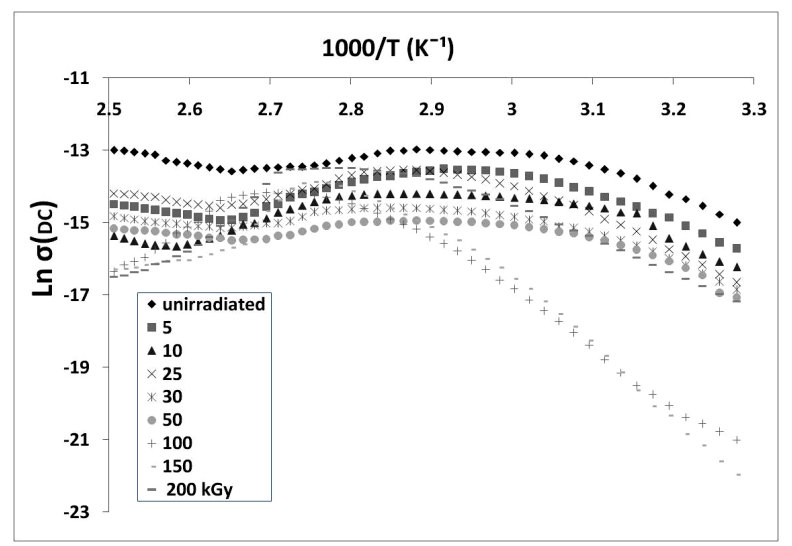

Figure 4. The logarithmic variation of conductivity ( versus 1000/T $\left({ }^{\circ} \mathrm{K}^{-1}\right)$ for the AAc/MMA copolymer films.

where $\sigma_{o}$ is the temperature independent constant, $\mathrm{K}$ is the Boltzmann constant and $\Delta E_{a}$ is the electrical activation energy.

All the plots of Figure 4 indicate that the maintenance of four segments obeying the normal Arrhenius equation. It can be seen that the general trend of the conductivity-temperature curves is similar; the curves themselves sometimes overlap and intersect at a relatively higher temperature range [A. Shehap et al, 1998]. From the inspection of this figure, it is clear that the DC conductivity $\sigma_{D C}$ decreases as the $\gamma$-dose increases. However, the samples irradiated at 100 and $150 \mathrm{kGy}$ show a higher decrease in $\sigma_{D C}$ when compared with the unirradiated sample and the irradiated films with doses from 5 to 50 $\mathrm{kGy}$. The $\sigma_{D C}$ of the sample irradiated with $200 \mathrm{kGy}$ is in the same conductivity range of the samples irradiated with lower doses which in agreement with the result of $\sigma_{D C}$ at room temperature.

From Table 3, the values of the electrical activation 
Table 3. The values of activation energy $\Delta E \quad(\mathrm{eV})$ of the AAc/MMA copolymer films and their correlation coefficients.

\begin{tabular}{|c|c|c|c|c|c|c|c|c|}
\hline \multirow{2}{*}{ Dose (kGy) } & \multicolumn{8}{|c|}{ The activation energy $\Delta E(\mathrm{eV})$} \\
\hline & $300-338^{\circ} \mathrm{K}$ & $\mathbf{R}^{2}(\%)$ & $338-348^{\circ} \mathrm{K}$ & $R^{2}(\%)$ & 348- $379^{\circ} \mathrm{K}$ & $\mathbf{R}^{2}(\%)$ & $379-400^{\circ} \mathrm{K}$ & $\mathbf{R}^{2}(\%)$ \\
\hline unirradiated & 0.69 & 96.7 & 0.078 & 97.2 & 0.249 & 95.7 & 0.37 & 98.2 \\
\hline 5 & 0.68 & 99.0 & 0.098 & 95.1 & 0.489 & 96.0 & 0.29 & 99.7 \\
\hline 10 & 0.63 & 94.0 & 0.058 & 96.1 & 0.508 & 94.8 & 0.37 & 94.7 \\
\hline 25 & 0.73 & 97.4 & 0.727 & 98.0 & 0.443 & 98.0 & 0.27 & 97.6 \\
\hline 30 & 0.64 & 95.3 & 0.080 & 94.3 & 0.294 & 94.6 & 0.23 & 97.2 \\
\hline $\mathbf{5 0}$ & 0.76 & 95.0 & 0.087 & 94.4 & 0.276 & 93.2 & 0.19 & 97.9 \\
\hline 100 & 1.36 & 99.3 & 0.708 & 94.8 & 0.708 & 94.8 & 1.14 & 97.8 \\
\hline 150 & 1.74 & 99.7 & 0.925 & 99.5 & 1.745 & 93.2 & 0.35 & 97.3 \\
\hline 200 & 0.84 & 99.9 & 0.377 & 95.3 & 0.067 & 99.5 & 1.19 & 94.4 \\
\hline
\end{tabular}

energy of the unirradiated AAc/MMA film and the irradiated films with doses from 5 to $50 \mathrm{kGy}$ are in the same range while the activation energies of the films irradiated with 100 and $150 \mathrm{kGy}$ are higher in value than that of those irradiated with lower dose. Then at $200 \mathrm{kGy}$ the activation energies lie in the same range of the lower doses (5-50 kGy). That may be attributed to the fact at 100 and $150 \mathrm{kGy}$ the polymeric structure got morecrosslinked than that of lower doses and therefore need more energy to start electric conduction. At $200 \mathrm{kGy}$, the irradiation broke some of the crosslinked bond and chain scission started to dominate over crosslinking.

\subsection{AC Measurements}

Measurements of the dielectric parameters of the samples have also been carried out, and the obtained results were used for evaluation of the dielectric constant $\left(\varepsilon^{\prime}\right)$ and dielectric loss $\left(\varepsilon^{\prime \prime}\right)$, applying the Debye's equations [R. M. Radwan et al., 2004]:

$$
\begin{aligned}
& \varepsilon^{\prime}=\varepsilon_{\infty}^{\prime}+\frac{\varepsilon_{s}^{\prime}-\varepsilon_{\infty}^{\prime}}{1+\omega^{2} \tau^{2}} \\
& \varepsilon^{\prime \prime}=\frac{\left(\varepsilon_{s}^{\prime}-\varepsilon_{\infty}^{\prime}\right) \omega \tau}{1+\omega^{2} \tau^{2}}
\end{aligned}
$$

where $\varepsilon_{s}^{\prime}$ is the dielectric constant at static field, $\varepsilon_{\infty}^{\prime}$ is the dielectric constant at the end of the frequency range (minimum value of $\varepsilon^{\prime}$ ) and $\omega=2 \pi f$ and $(\tau)$ is the relaxation time. By simple mathematical manipulation, one can get the dielectric parameters in the form of the equation representing a straight line, namely

$$
\frac{\varepsilon^{\prime \prime}}{\omega}=\left(\varepsilon^{\prime}-\varepsilon_{\infty}\right) \tau
$$

Equation (7a) is more useful for the higher frequencies [R. M. Radwan et al., 2008], it can be written as

$$
\log \left(\frac{\varepsilon^{\prime \prime}}{\omega}\right)=\log \left(\varepsilon^{\prime}-\varepsilon_{\infty}\right)+\log (\tau)
$$

The relaxation time can be determined from the intercept of the straight line in the equation (7b) which was used in the Debye fitting in equations (5) and (6). Figures 5 and 6 show the variation of the dielectric con-

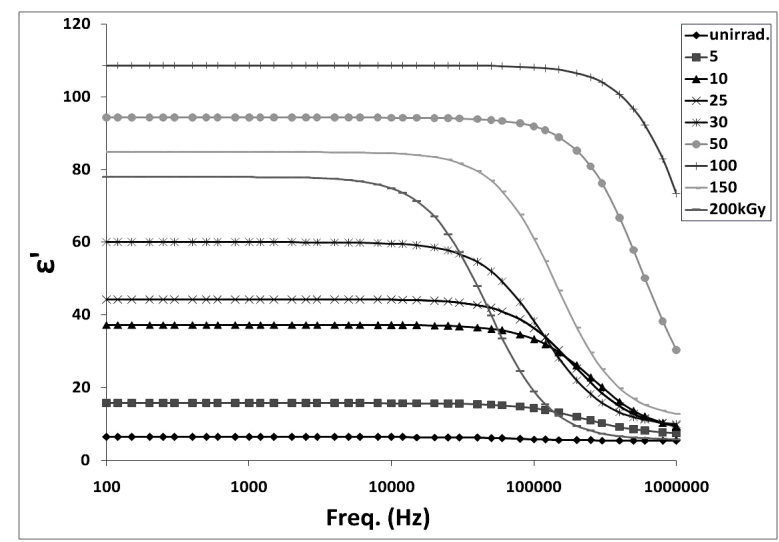

Figure 5. The variation of the Dielectric constant $\left(\varepsilon^{\prime}\right)$ with frequency of the AAc/MMA copolymer films.

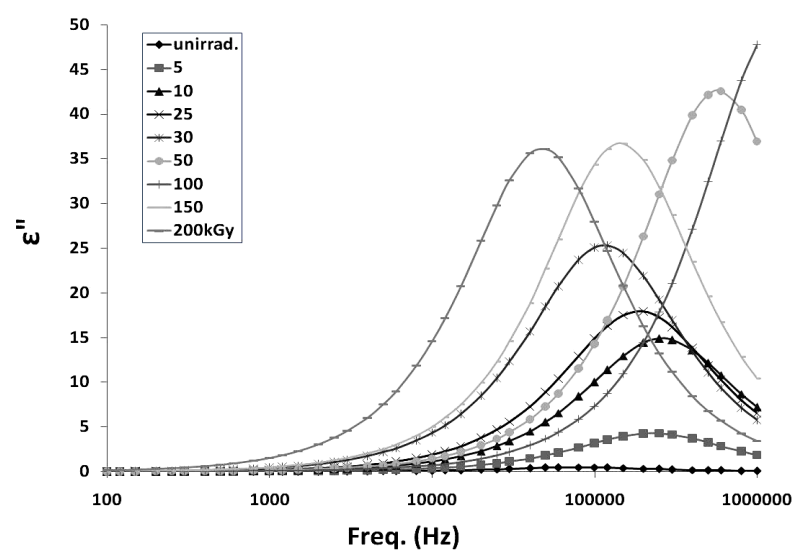

Figure 6. The variation of the fitted dielectric loss $\left(\varepsilon^{\prime \prime}\right)$ with frequency for the AAc/MMA copolymer films. 
stant $\left(\varepsilon^{\prime}\right)$ and dielectric loss $\left(\varepsilon^{\prime \prime}\right)$ with frequency for the copolymer films within the frequency range $100 \mathrm{~Hz}$ to $1 \mathrm{MHz}$ at room temperature respectively.

From the obtained results one can notice that the dielectric constant and loss increase with dose up to 100 $\mathrm{kGy}$ then decrease at doses 150 and $200 \mathrm{kGy}$. The increase of $\varepsilon^{\prime}$ and $\varepsilon^{\prime \prime}$ value, due to the irradiation of the polymer in air is attributed to the increase of the number of dipoles in the polymer matrix where may be resulted from the increase of the number of $\mathrm{C}=\mathrm{O}$ double bonds and $\mathrm{C}-\mathrm{H}$ bonds in the polymer matrix. On the other hand, the increase of the irradiation does to 150 and $200 \mathrm{kGy}$ may increase the number of free radicals that may react to decrease the number of dipoles in the samples. [R.M. Radwan et al. 2008].

\section{Conclusion}

The effect of gamma irradiation on AAc/MMA copolymer films has been investigated. The gamma irradiation, up to $100 \mathrm{kGy}$, leads to crosslinking reaction domination over chain scission causing an increase in the thermal stability of the films and a decrease in the DC conductivity $\left(\sigma_{D C}\right)$ of the copolymer films; its value falls about three orders of magnitude from its original value. The optical band gap, band tail width and electrical activation values for the sample irradiated with $100 \mathrm{kGy}$ were higher than that of lower doses. Also the values of the dielectric parameters were found to increase with irradiation dose up to $100 \mathrm{kGy}$. These results indicate that the irradiated copolymer films with dose $100 \mathrm{kGy}$ may be suitable for applications such as cable and wire isolation for electronic systems.

\section{REFERENCES}

[1] El-Hag Ali, H. A. Shawky, H. A. Abd El Rehim, E.A. Hegazy, Synthesis and characterization of PVP/AAc copolymer hydrogel and its applications in the removal of heavy metals from aqueous solution, European Polymer Journal 39, 2337-2344 (2003).

[2] Andrzej G. Chmielewski , Mohammad Haji-Saeid, Shamshad Ahmed, Progress in radiation processing of polymers, Nuclear Instruments and Methods in Physics Research B 236, 44-54 (2005).

[3] Shehap, R. A. Abd Allah, A. F. Basha, F. H. Abd EL-Kader, Electrical Properties of Gamma Irradiated, Pure, and Nickel Chloride-Doped Polyvinyl Alcohol Films, Journal of Applied Polymer Science, Vol. 68, 687-698 (1998).

[4] Banford HM, Fouracre RA, Faucitano A, Buttafava A, Martinotti F. The influence of gamma irradiation and chemical structure on the dielectric properties of polypropylene. Radiat Phys Chem 48(1), 129-30 (1996).

[5] Erjun Tang, Guoxiang Cheng, Xiaolu Ma, Preparation of
nano-ZnO/PMMA composite particles via grafting of the copolymer onto the surface of zinc oxide nanoparticles, Powder Technology 161, 209-214 (2006).

[6] F. Sharaf, M. H. I. El-Eraki, A. R. El-Gohary \& F. M. A. Ahmed, The optical and mechanical properties before and after gamma irradiation of poly (viny1 alcohol) films doped with lead acetate, Polymer Degradation and Stability 47, 343-348 (1995).

[7] F. Yakuphanoglu, G. Barım, I. Erol, The effect of $\mathrm{FeCl}_{3}$ on the optical constants and optical band gap of MBZMA-co-MMA polymer thin films, Physica B 391, 136-140 (2007).

[8] Hiroshi Yoshida and Tsuneki Ichikawa,Temperature effect on the radiation-degradation of poly(methyl methacrylate), Radiat. Phys. Chem. Vol. 46, No. 4-6, 921-924 (1995).

[9] H. M. Abdel-Hamid, Y. H. A. Fawzy and S. M. El-Sayed, Optical and Morphological Properties of Electron -beam Irradiated High-Density Thin Poly Ethylene Films, Egypt. J. Rad. Sci., Applic. Vol. 18, No. 2, 465-479 (2005).

[10] L. C. Lopérgolo, L. H. Catalani, L. D. B. Machado, P. R. Rela, A.B. Lugão, Development of reinforced hydrogelsI. Radiation induced graft copolymerization of methyl methacrylate on non-woven polypropylene fabric, Radiation Physics and Chemistry 57, 451-454, (2000).

[11] Maria Omastova, Juraj Pavlinec, Jurgen Pionteck ,Frank Simon,"Synthesis, Electrical Properties and Stability of Polypyrrole-Containing Conducting Polymer Composite, Polymer International 43, 109-116 (1997).

[12] R. M. Radwan, S. lotfy, O. S. Desouky, Enhancement of the electrical performance of poly(vinyl) alcohol by doping with chlorophyll and gamma irradiation, Nucl. Instr. and Meth. in Phys. Res. B 266, 3953-3958 (2008).

[13] R. M. Radwan, Y. H. A. Fawzy, A. El-Hag Ali, Electrical behaviour of butyl acrylate / methyl methacrylate copolymer films irradiated with $1.5 \mathrm{MeV}$ electron beam, Radiation Physics and Chemistry, 77,179-185 (2008).

[14] R. M. Radwan, Y. H. A. Fawzy, H. A. Ashry, F. A. S. Soliman, Characterization of the electrical behavior of rare earth elements during the upgrading of monazite. J. Phys. D 37, 764-769(2004).

[15] R. Mishra, S. P. Tripathy, D. Sinha, K. K. Dwivedi, S. Ghosh, D.T. Khathing, M. Muller, D. Fink, W.H. Chung, Optical and electrical properties of some electron and proton irradiated polymers, Nuclear Instruments and Methods in Physics Research B 168, 59-64 (2000).

[16] R. Mishra, S. P. Tripathya, K. K. Dwivedi, D. T. Khathing, S. Ghosh, M. Muller, D. Fink, Electron induced modification in polypropylene, Radiation Measurements 33, 845-850 (2001).

[17] R. Sosa Fonseca, M. Flores, R. Rodriguez T., J. Hernández, A. Munõz F., Evidence of energy transfer in $\mathrm{Er}^{3+}$-doped PMMA-PAAc copolymer samples, Journal of Luminescence 93, 327-332 (2001).

[18] Sangita Rajvaidya, R. Bajpai, A. K. Bajpai, Effect of gamma irradiation on the interpenetrating networks of 
gelatin and polyacrylonitrile: Aspect of crosslinking using microhardness and crosslink density measurements, Journal of Applied Polymer Science, Vol. 101, 2581-2586 (2006).

[19] Tadaaki Inoue, Guohua Chen, Katsuhiko Nakamae, Allan
S. Hoffman, An AB block copolymer of oligo(methyl methacrylate) and poly(acrylic acid) for micellar delivery of hydrophobic drugs, Journal of Controlled Release 51, 221-229(1998). 